\title{
Fish oil supplementation and insulin sensitivity: a systematic review and meta- analysis
}

\author{
Huanqing Gao ${ }^{1 \dagger}$, Tingting Geng ${ }^{2,4 \dagger}$, Tao Huang ${ }^{2,3^{* \dagger}}$ and Qinghua Zhao ${ }^{4^{*}+}$
}

\begin{abstract}
Background: Fish oil supplementation has been shown to be associated with a lower risk of metabolic syndrome and benefit a wide range of chronic diseases, such as cardiovascular disease, type 2 diabetes and several types of cancers. However, the evidence of fish oil supplementation on glucose metabolism and insulin sensitivity is still controversial. This meta-analysis summarized the exist evidence of the relationship between fish oil supplementation and insulin sensitivity and aimed to evaluate whether fish oil supplementation could improve insulin sensitivity.

Methods: We searched the Cochrane Library, PubMed, Embase database for the relevant studies update to Dec 2016. Two researchers screened the literature independently by the selection and exclusion criteria. Studies were pooled using random effect models to estimate a pooled SMD and corresponding 95\% Cl. This meta-analysis was performed by Stata 13.1 software.

Results: A total of 17 studies with 672 participants were included in this meta-analysis study after screening from 498 published articles found after the initial search. In a pooled analysis, fish oil supplementation had no effects on insulin sensitivity compared with the placebo (SMD 0.17, $95 \% \mathrm{Cl}-0.15$ to $0.48, p=0.292$ ). In subgroup analysis, fish oil supplementation could benefit insulin sensitivity among people who were experiencing at least one symptom of metabolic disorders (SMD 0.53, 95\% Cl 0.17 to 0.88, $p<0.001$ ). Similarly, there were no significant differences between subgroups of methods of insulin sensitivity, doses of omega-3 polyunsaturated fatty acids ( $n-3$ PUFA) of fish oil supplementation or duration of the intervention. The sensitivity analysis indicated that the results were robust.
\end{abstract}

Conclusions: Short-term fish oil supplementation is associated with increasing the insulin sensitivity among those people with metabolic disorders.

Keywords: Fish oil, Insulin sensitivity, Omega-3 polyunsaturated fatty acids, Meta-analysis

\section{Background}

Type 2 diabetes mellitus (T2DM) is one of the most common chronic diseases caused a dramatic public health burden overall and T2DM is also linked to a higher risk of all types cancer incidence, which is reported to be one of the

\footnotetext{
*Correspondence: huang_tao@nuhs.edu.sg; 1057955088@qq.com

†Equal contributors

2Epidemiology Domain, Saw Swee Hock School of Public Health, Singapore, Singapore

${ }^{4}$ Department of Nursing, The First Affiliated Hospital of Chongqing Medical University, No. 1 Youyi Lu, Yuzhong District, 400016 Chongqing, People's Republic of China

Full list of author information is available at the end of the article
}

leading causes of morbidity and mortality worldly [1]. It is estimated that the prevalence of T2DM will increase to $4.4 \%$ in 2030 and the total number of all age-group people is projected to rise to over 250 million by then [2]. The direct economic burden related to T2DM, gestational diabetes and impaired glucose tolerance exceeded over $\$ 300$ billion in 2012 in the USA [3]. It has been systematically reported that fatty acids have great influences on a series of chronic diseases, such as T2DM, cardiovascular diseases and metabolic syndrome [4-7]. Previous metaanalysis studies have reported that fish consumption and dietary long-chain omega-3 polyunsaturated fatty acids 
(n-3 PUFA) decreased the risk of T2DM $[8,9]$. The active elements of fish oil supplementation are recognized as $n-3$ PUFA (DHA and EPA) $[4,5]$. In this study, to reduce the bias, only fish-derived n-3 PUFA was included rather than the plant-derived intervention studies.

Insulin sensitivity is a measure of insulin responsiveness. Poor insulin sensitivity is associated with T2DM and metabolic syndrome $[10,11]$. The results of randomized control trials (RCTs) investigating the association between n-3 PUFA and insulin sensitivity were inconsistent [12-15]. The different results may be caused by the various study population, small sample size, short study duration, different dose of n-3 PUFA intervention. In 2011, Akinkuolie et al. conducted a meta-analysis about the relationship between n-3 PUFA and insulin sensitivity [16], which reported that n-3 PUFA had no effects on insulin sensitivity. However there have been new RCTs published after this metaanalysis above. Therefore, we conducted a comprehensive and updated meta-analysis to systematically examine the effect of fish oil supplementation on insulin sensitivity.

\section{Methods}

\section{Search strategy}

The database of Cochrane, PubMed, and Embase up to Dec 2016 were searched and this report was performed according to the Preferred Reporting Items for Systematic Reviews and Meta-Analysis (PRISMA) statement [17]. The search was based on combinations of synonyms for fish oil (omega-3 fatty acid, n-3 fatty acid, DHA, EPA), insulin resistance and insulin sensitivity. References lists of retrieved articles were screened manually to achieve maximum sensitivity of the search strategy and identify all randomized control trials (RCTs). The measures of insulin sensitivity estimate included of hyperinsulinemic-euglycemic glucose clamp, HOMA of insulin resistance (HOMA-IR), Quantitative Insulin Sensitivity Check Index (QUICKI) and glucose tolerance.

\section{Search selection}

RCTs (either parallel or crossover design) were selected by two authors (TT G, HQ G) following the inclusion criteria: human RCTs with fish oil supplementation intervention, including of omega-3 fatty acid, n-3 fatty acid, DHA, EPA, and the outcomes were values of baseline and after intervention insulin sensitivity or insulin resistance. Data of insulin sensitivity estimates should be sufficient to calculate mean and standard deviation (SD). The participants of studies were adults, who were over 18 years old. The control group could receive corn oil, olive oil or other types of placebos. However, the placebo could not be any capsule containing n-3 fatty acid elements. The studies that target populations were children or adolescents under 18 years old were excluded. Previous studies have demonstrated that physical activity could increase in insulin sensitivity $[18,19]$. We also excluded the studies that combined fish oil supplementation with other physical activities as an intervention. We also excluded the studies that combined fish oil supplementation with other physical activities as an intervention. Nonclinical trials, observational studies or reviews were excluded. To avoid the carry-over effect, all the crossover design studies were extracted the data from the first period only, managed as parallel group trials. Therefore, crossover design studies without specific data at the end of the first intervention phase were excluded [20]. Only English trials were included in this study. A senior author (QH Z or $\mathrm{TH})$ was consulted when there were discrepancies about the study inclusion.

\section{Data extraction and quality assessment}

A standard data extraction form was used by two authors independently to collect the Information, which included name of the first author, publication year, study design, inclusion/exclusion criteria, sample size, participants' characteristics, intervention details (e.g. dosage, type, frequency, duration), placebo, the outcomes information (e.g. Insulin sensitivity, insulin resistance) and compliance. Sample size, mean and SD were extracted from intervention group and control group. Only the first duration data were obtained from the cross-over design studies. Two researchers (TT G, HQ G) assessed the methodological quality of each trial included in the study independently. When there were disagreements of the data extraction, a third author $(\mathrm{QH} \mathrm{Z}$ or $\mathrm{TH})$ was consulted. Cochrane Collaboration's tool was used to assess the quality of the trials, which included of randomization procedures, allocation concealment, blinding of participants, researchers and outcome assessors, incomplete outcome data, non-elective reporting, other bias and compliance. If all features were adequate, the quality of the studies was a low risk of bias. If one or more features were unclear, the risk of bias was unclear. If one or more features were inadequate or negative, it was at high risk of bias.

\section{Data synthesis and analysis}

The mean and SD values of intervention group and control group at the end of the fish oil supplementation intervention were extracted to calculate the effect size [21]. If SEs were reported rather than SDs, then SDs were calculated by equation $\mathrm{SD}=\mathrm{SE} \times \sqrt[2]{n}$. If $95 \% \mathrm{CI}$ was reported, $\mathrm{SD}$ was calculated by equation $\mathrm{SD}=\sqrt[2]{n}$ $\times$ (upper-lower) $/ 2 \times \mathrm{t}$, where $\mathrm{n}$ is the number of subjects [22]. A random-effects model (using the DerSimonian-Laird method) and the generic inverse 
variance method were used to derive pooled estimates across studies [23]. The heterogeneity was assessed through the $\mathrm{I}^{2}$ statistic and $p$-value. $\mathrm{I}^{2}>50 \%$ was considered as the substantial amount of statistical heterogeneity [24]. The publication bias was evaluated by Egger's and Begg's method. Sensitivity analysis was conducted when heterogeneity was more than $50 \%$ combined $p$-value less than 0.05 . Influence analysis method was used to perform the sensitivity test. Omitting one study once till all the studies were picked out during the sensibility test. The studies, which affected the results primarily to cause heterogeneity, were excluded. In order to assess the potential sources of heterogeneity, subgroup analysis were designed to conduct according to participants' characteristics (healthy persons, metabolic disorders participants, T2DM), measurement of insulin sensitivity (clamps, HOMA, QUICKI, glucose tolerance), n-3 PUFA dose (low dose $<2 \mathrm{~g}$, high dose $\geq 2 \mathrm{~g}$ ) [25], intervention duration (short-term $<12 \mathrm{w}$, long-term $\geq 12 \mathrm{w}$ ) [26]. All tests were performed using statistical software package STATA version 13.1 and two-sided $P$ value $<0.05$ were considered statistically significant.

\section{Results}

\section{Study identification}

Seventeen studies included in this meta-analysis after the screening involving 672 participants. 498 published articles were found after the initial search. One article retrieved from hand search through references of included studies. After the titles and abstracts screening, there were 53 articles left. Studies were excluded by non-RCTs study design or not relevant to the topic, or the participants were under 18 years old. Studies were excluded due to the fish oil supplementation was not the only intervention or there were no specific data of the insulin sensitivity estimates. Crossover design studies were excluded without the specific data of the first period of interventions. After the full-text screening, 17 trails met the criteria and were assessed the study quality. The details of the studies selection process are shown in Fig. 1.

\section{Study characteristics}

Descriptive data of the included studies were summarized in Table 1. All the included trials were published from 1995 to 2014. One of the 17 studies was crossover design [27] and others were parallel design. The participants from 8 studies included were diagnosed as type 2 diabetes $[14,15,28-30]$ and participants of 4 studies were healthy persons $[27,31,32]$. Others were patients with at least one of the metabolic disorder symptoms [12, 13, 33-35], including of abnormal boday mass index (BMI), hypertension, and lipid metabolism disorders. Four of the included studies used clamps as the methods of insulin sensitivity estimates [15, 28, 29]. HOMA [1214, 27, 30, 34, 36, 37] and QUICKI [31, 38, 39] were used by 9 studies and 3 trials, respectively. One of the trials used glucose tolerance method [33]. The doses of active ingredients of fish oil (n-3 fatty acids) were ranged from $1 \mathrm{~g} / \mathrm{d}$ to $4 \mathrm{~g} / \mathrm{d}$. Duration of the interventions was ranged from 4 weeks to 24 weeks. All the trials have reported the baseline values of insulin sensitivity and the data of insulin sensitivity after interventions.

\section{Quality assessment}

The Cochrane Collaboration's tool for assessing the risk of bias included the adequate sequence generation,

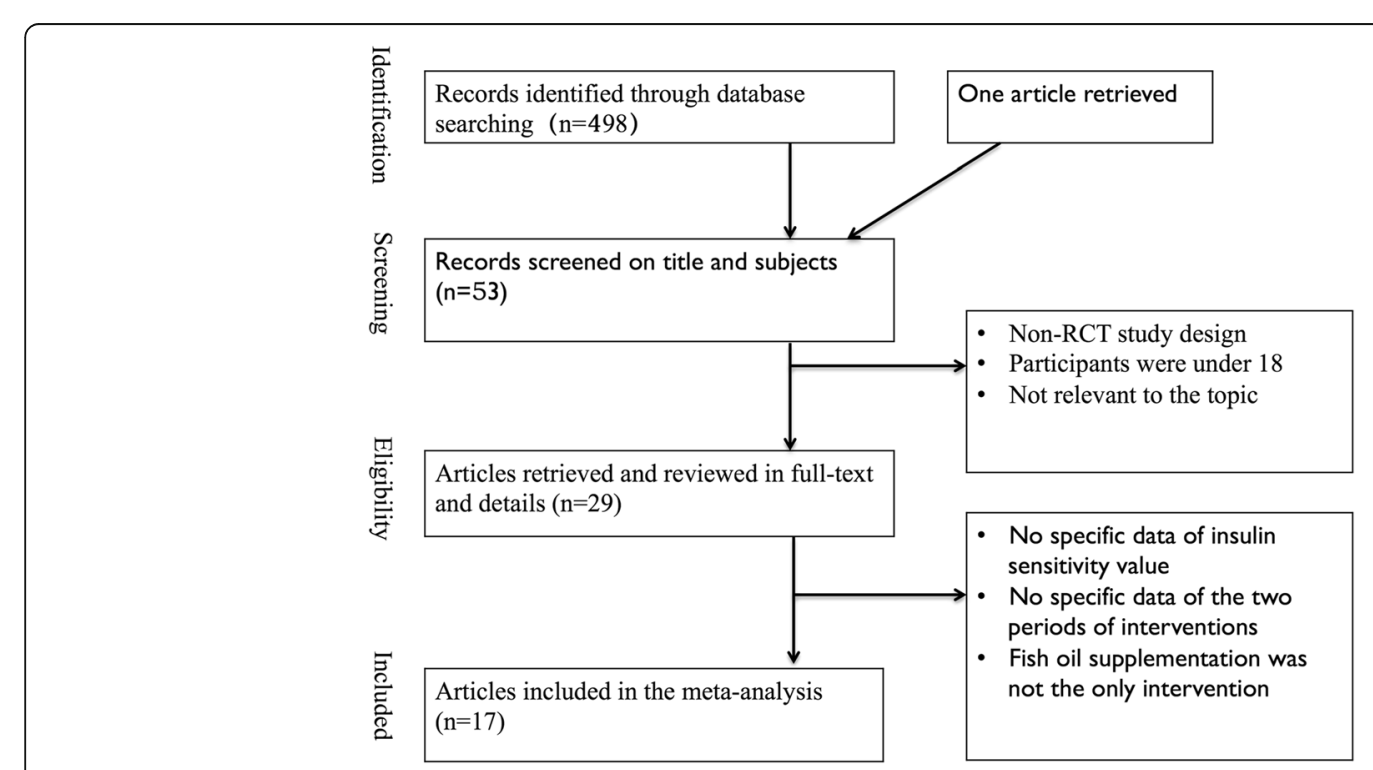

Fig. 1 Summary of the procedure used to select studies for inclusion in the meta-analysis 
Table 1 The characteristic of the RCTs included in our study

\begin{tabular}{|c|c|c|c|c|c|c|c|c|c|}
\hline Study (year) & Population characteristics & $\begin{array}{l}\text { Study } \\
\text { design }\end{array}$ & $\begin{array}{l}\text { Age } \\
\text { (years old) }\end{array}$ & Gender & n-3PUFA dose & Duration & Control & IS measure & Compliance \\
\hline $\begin{array}{l}\text { Rivellese } \\
1996[28]\end{array}$ & $\begin{array}{l}16 \text { postmenopausal women } \\
\text { with NIDDM and type } 2 B \text { or } \\
\text { IV hyperlipoproteinemia }\end{array}$ & RCT & $40-75$ & $F=16$ & $\begin{array}{l}2.5 \mathrm{~g} \text { in the } \\
\text { first } 2 \mathrm{mo} \text {; } \\
1.7 \mathrm{~g} \text { in the } \\
\text { last } 4 \mathrm{mo}\end{array}$ & $24 w$ & Olive oil & $\begin{array}{l}\text { Euglycemic } \\
\text { hyperinsulinemic } \\
\text { clamps }\end{array}$ & $\overline{\text { Acceptable }}$ \\
\hline $\begin{array}{l}\text { Krysiak } 2011 \\
{[12]}\end{array}$ & $\begin{array}{l}66 \text { Patients with lipid } \\
\text { metabolism abnormalities }\end{array}$ & RCT & $35-70$ & $\begin{array}{l}M=43 \\
F=23\end{array}$ & $2 \mathrm{~g} / \mathrm{d}$ & $12 w$ & Placebo & HOMA ratio & $90 \%-100 \%$ \\
\hline $\begin{array}{l}\text { Rizza } 2009 \\
{[13]}\end{array}$ & $\begin{array}{l}50 \text { healthy patients } \\
\text { with } \geq 1 \text { parent with } \mathrm{DM} 2\end{array}$ & RCT & $29.9 \pm 6.2$ & $\begin{array}{l}M=25 \\
F=25\end{array}$ & $2 \mathrm{~g} / \mathrm{d}$ & $12 w$ & Olive oil & QUICKI & $93 \%$ \\
\hline $\begin{array}{l}\text { Woodman } \\
2002[14]\end{array}$ & $\begin{array}{l}59 \text { T2DM with oral } \\
\text { hypoglycemic medications }\end{array}$ & RCT & $40-75$ & $\begin{array}{l}M=39 \\
F=12\end{array}$ & $4 \mathrm{~g} / \mathrm{d}$ & $6 w$ & Olive oil & $\begin{array}{l}\text { Euglycemic } \\
\text { hyperinsulinemic } \\
\text { clamps }\end{array}$ & $98 \%$ \\
\hline $\begin{array}{l}\text { Mostad } 2006 \\
{[15]}\end{array}$ & $\begin{array}{l}26 \text { T2DM without } \\
\text { hypertriacylglycerolemia }\end{array}$ & RCT & $40-75$ & $\begin{array}{l}M=13 \\
F=14\end{array}$ & $2.4 \mathrm{~g} / \mathrm{d}$ & $9 w$ & Corn oil & $\begin{array}{l}\text { Isoglycemic } \\
\text { hyperinsulinemic } \\
\text { clamps }\end{array}$ & $96 \%$ \\
\hline $\begin{array}{l}\text { Sarbolouki } \\
2013[30]\end{array}$ & 67 patients with T2DM & RCT & $35-55$ & $\begin{array}{l}M=26 \\
F=41\end{array}$ & $2 \mathrm{~g} / \mathrm{d}$ & $12 w$ & Corn oil & HOMA-IR & $96 \%$ \\
\hline $\begin{array}{l}\text { Morvarid } \\
2007\end{array}$ & $\begin{array}{l}26 \text { postmenopausal } \\
\text { women with T2DM }\end{array}$ & RCT & $40-60$ & $F=26$ & $3 \mathrm{~g} / \mathrm{d}$ & $8 w$ & Paraffin oil & HOMA-S & $90 \%$ \\
\hline $\begin{array}{l}\text { Darshan } \\
2011\end{array}$ & 34 healthy men & RCT & $39-66$ & $M=34$ & $3 \mathrm{~g} / \mathrm{d}$ & $12 w$ & Olive oil & HOMA-IR & $85 \%$ \\
\hline $\begin{array}{l}\text { Fakhrzadeh } \\
2010 \text { [39] }\end{array}$ & 134 elderly T2DM & RCT & $\geq 65$ & $\begin{array}{l}F=79 \\
M=55\end{array}$ & $1 \mathrm{~g} / \mathrm{d}$ & $24 w$ & $\begin{array}{l}\text { Medium } \\
\text { chain } \\
\text { triglycerides } \\
\text { oil }\end{array}$ & HOMA-IR & $93 \%$ \\
\hline $\begin{array}{l}\text { Michael } \\
2013\end{array}$ & $\begin{array}{l}34 \text { non diabetic subjects } \\
\text { with either impaired } \\
\text { glucose tolerance } \\
\text { impaired fasting glucose, } \\
\text { or at least three features } \\
\text { of the metabolic syndrome }\end{array}$ & RCT & $27-43$ & $\begin{array}{l}M=12 \\
F=22\end{array}$ & $4 \mathrm{~g} / \mathrm{d}$ & $12 w$ & Corn oil & $\begin{array}{l}\text { Intravenous } \\
\text { glucose tolerance } \\
\text { tests }\end{array}$ & $97 \%$ \\
\hline $\begin{array}{l}\text { Abete } 2008 \\
{[35]}\end{array}$ & $\begin{array}{l}32 \text { subjects } \\
(\mathrm{BMI}=31.6 \pm 3.5)\end{array}$ & RCT & $36 \pm 7$ & $\begin{array}{l}F=14 \\
M=18\end{array}$ & $1.69 \mathrm{~g} / \mathrm{d}$ & $8 w$ & Control diet & HOMA index & $85 \%$ \\
\hline Farsi 2013 & 45 patients with T2DM & RCT & $30-65$ & NA & $4 \mathrm{~g} / \mathrm{d}$ & $10 w$ & Corn oil & QUICKI & $98 \%$ \\
\hline $\begin{array}{l}\text { Toft } 1995 \\
{[48]}\end{array}$ & $\begin{array}{l}78 \text { persons with untreated } \\
\text { hypertension }\end{array}$ & RCT & $20-61$ & $\begin{array}{l}M=50 \\
F=28\end{array}$ & $4 \mathrm{~g} / \mathrm{d}$ & $16 w$ & Corn oil & $\begin{array}{l}\text { Euglycemic } \\
\text { hyperinsulinemic } \\
\text { clamp }\end{array}$ & $96 \%$ \\
\hline $\begin{array}{l}\text { Crochemore } \\
2012[37]\end{array}$ & $\begin{array}{l}27 \text { women with high blood } \\
\text { pressure and T2DM }\end{array}$ & RCT & $60.64 \pm 7.82$ & $F=27$ & $2.5 \mathrm{~g} / \mathrm{d}$ & $4 w$ & Gelatin & QUICKI & $100 \%$ \\
\hline $\begin{array}{l}\text { Kondo } 2014 \\
{[26]}\end{array}$ & 23 postmenopausal women & RCT & $69.7 \pm 6.6$ & $F=23$ & $\geq 3 \mathrm{~g}$ & $4 w$ & $\begin{array}{l}\text { Fish avoid } \\
\text { intake diet }\end{array}$ & HOMA-R & $100 \%$ \\
\hline
\end{tabular}

allocation concealment, blinding, incomplete outcome data, selective reporting and another risk of bias. All the trials rarely stated about the specific process of allocation concealment. Two studies were not double blinded properly and one study was single blinded. Two were not clear about the blinding. One of the studies did not report the exact information of the loss to follow-up and did not explain in detail either. Details of the quality assessment could be seen in Table 2 .

\section{Meta-analysis}

The forest plot of insulin sensitivity is shown in Fig. 2. The pooled analysis showed that fish oil supplementation had no effects on insulin sensitivity overall (SMD
$0.17,95 \% \mathrm{CI}-0.15$ to $0.48, p=0.292)$. The $\mathrm{I}^{2}$ test indicated that there was a substantial statistical heterogeneity across the included trials $\left(\mathrm{I}^{2}=58.1 \%, p=0.001\right)$.

\section{Subgroup analysis}

The results of the subgroup analysis present in Table 3 showed an association of lower risk in the group of people with metabolic disorders (SMD 0.53, 95\%CI 0.17-0.88, $p<0.001)$. We found fish oil had no effects on insulin sensitivity among the healthy people or people with T2DM. Also, subgroup analysis showed a positive effect of fish oil on insulin sensitivity among the short-term intervention group rather than the long-term intervention group (SMD $0.31,95 \%$ CI $0.01-0.61, p=0.04)$. There was no difference 
Table 2 Quality assessment of the included studies

\begin{tabular}{|c|c|c|c|c|c|c|c|}
\hline Study & $\begin{array}{l}\text { Random sequence } \\
\text { generation }\end{array}$ & $\begin{array}{l}\text { Allocation } \\
\text { concealment }\end{array}$ & $\begin{array}{l}\text { Blinding of } \\
\text { participants }\end{array}$ & $\begin{array}{l}\text { Blinding of } \\
\text { outcome }\end{array}$ & $\begin{array}{l}\text { Incomplete outcome data } \\
\text { addressed }\end{array}$ & $\begin{array}{l}\text { Non-elective } \\
\text { reporting }\end{array}$ & $\begin{array}{l}\text { Other } \\
\text { bias }\end{array}$ \\
\hline $\begin{array}{l}\text { Rivellese } 1996 \\
\text { [28] }\end{array}$ & $U$ & $U$ & $\mathrm{~L}$ & $L$ & L & $L$ & $L$ \\
\hline $\begin{array}{l}\text { Krysiak } 2011 \\
{[12]}\end{array}$ & $U$ & U & $U$ & $U$ & L & L & $U$ \\
\hline Rizza 2009 [13] & $U$ & U & L & L & L & L & L \\
\hline $\begin{array}{l}\text { Woodman } 2002 \\
\text { [14] }\end{array}$ & $U$ & L & L & L & L & L & L \\
\hline $\begin{array}{l}\text { Mostad } 2006 \\
{[15]}\end{array}$ & $U$ & U & L & L & L & L & L \\
\hline $\begin{array}{l}\text { Sarbolouki } \\
2013[30]\end{array}$ & U & U & L & L & L & L & L \\
\hline Morvarid 2007 & $U$ & U & L & L & L & L & L \\
\hline Darshan 2011 & $U$ & U & U & U & L & L & $U$ \\
\hline $\begin{array}{l}\text { Fakhrzadeh } \\
2010 \text { [39] }\end{array}$ & U & U & L & $L$ & L & $L$ & L \\
\hline Michael 2013 & $U$ & U & U & $U$ & U & $U$ & $U$ \\
\hline Abete2008 [35] & $U$ & U & U & $U$ & L & L & $U$ \\
\hline Farsi 2013 & $U$ & U & U & $U$ & L & L & $U$ \\
\hline Toft 1995 [48] & $U$ & U & L & L & L & L & L \\
\hline $\begin{array}{l}\text { Crochemore } \\
2012[37]\end{array}$ & $U$ & U & L & $\mathrm{H}$ & L & L & $\mathrm{H}$ \\
\hline $\begin{array}{l}\text { Kondo } 2014 \\
{[26]}\end{array}$ & $U$ & U & $\mathrm{H}$ & $\mathrm{H}$ & L & L & $\mathrm{H}$ \\
\hline
\end{tabular}

$H$ high risk, $L$ low risk, $U$ unclear

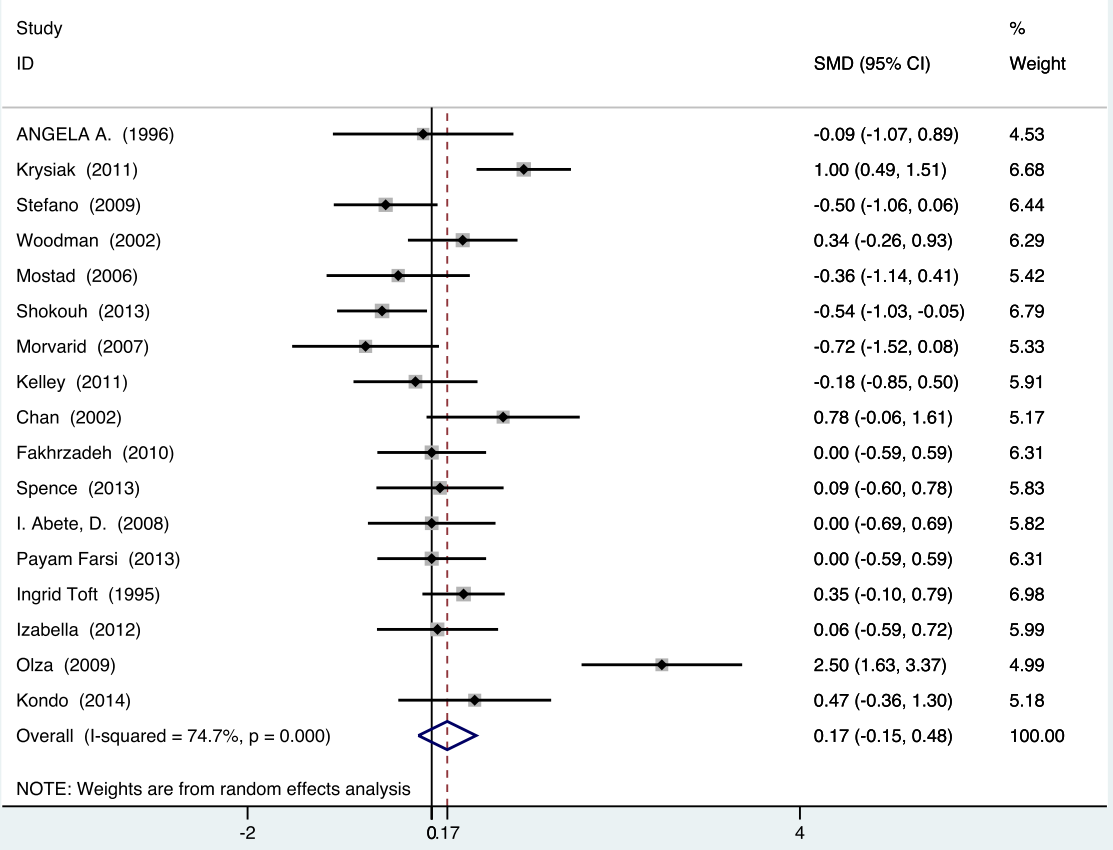

Fig. 2 Meta-analysis of insulin sensitivity of participants with fish oil supplementation 
Table 3 Subgroup analysis of fish oil consumption and insulin sensitivity

\begin{tabular}{|c|c|c|c|c|}
\hline Subgroup & No. Of studies & SMD (95\%IC) & $P$ value & $I^{2}$ value (\%) \\
\hline \multicolumn{5}{|c|}{ Methods of insulin sensitivity } \\
\hline Clamps & 4 & $0.10(-0.18-0.44)$ & 0.41 & 0.00 \\
\hline HOMA & 9 & $0.28(-0.08-0.63)$ & 0.13 & 66.6 \\
\hline QUICKI & 3 & $0.15(-0.68-0.97)$ & 0.73 & 81.6 \\
\hline Glucose tolerance & 1 & $0.19(-0.05-0.42)$ & 0.79 & 58.1 \\
\hline \multicolumn{5}{|l|}{ Population } \\
\hline $\mathrm{T} 2 \mathrm{DM}$ & 8 & $0.12(-0.22-0.45)$ & 0.50 & 57.1 \\
\hline Metabolic disorders & 5 & $0.53(0.17-0.88)$ & $<0.001$ & 42.6 \\
\hline Healthy people & 4 & $-0.15(-0.53-0.24)$ & 0.46 & 22.8 \\
\hline \multicolumn{5}{|l|}{ Dose } \\
\hline$\geq 2 \mathrm{~g}$ & 14 & $0.17(-0.11-0.46)$ & 0.24 & 64.2 \\
\hline$<2 \mathrm{~g}$ & 3 & $0.26(-0.04-0.56)$ & 0.09 & 0.00 \\
\hline \multicolumn{5}{|l|}{ Duration } \\
\hline$\geq 12 w$ & 9 & $0.09(-0.25-0.44)$ & 0.60 & 70.2 \\
\hline$<12 w$ & 8 & $0.31(-0.01-0.61)$ & 0.04 & 29.4 \\
\hline
\end{tabular}

in the subgroups of intervention dosage and methods of insulin sensitivity values. Results of subgroup analysis are shown in Table 3.

\section{Sensitivity analysis and publication bias}

In sensitivity analysis, it could be noticed that there was no any trial's estimated value being out of the $95 \% \mathrm{CI}$ and the combined 95\% CI. The summary results did not differ significantly when we omitted studies one at a time. Therefore, results remained stable and robust. There was no suggestion of small study effect based on visual inspection of the funnel plot. Results of the Egger's $(p=0.78)$ and Begg's $(p=0.43)$ tests showed that there was no potential publication bias.

\section{Discussion}

The findings from this meta-analysis, based on 672 participants from 17 studies, demonstrated that fish oil supplementation did not improve insulin sensitivity overall. In subgroup analysis, among participants with metabolic disorders, fish oil supplementation could reduce the risk of insulin resistance by $47 \%$. Our results were consistent with the meta-analysis reported in 2011 showing that fish oil supplementation had no effects on insulin sensitivity; however, among participants with metabolic syndrome, fish oil is associated with lower risk of insulin resistance [16, 40]. Participants in the meta-analysis were only healthy people and T2DM people; therefore, an important group of patients with metabolic disorders was neglected in the research. It has reported that insulin sensitivity is strongly associated with metabolic syndrome [41]. In addition, the previous meta-analysis did not address issues relating to dose and duration of intervention. Our study made subgroup analysis according to dose and duration of intervention, though the results were negative. Observational studies have reported that high dose of n-3 PUFA were effective to prevent chronic diseases rather than low dose and high dose n-3 PUFA could reduce serum triglyceride concentrations effectively and hypertriglyceridemia [25]. However, epidemiological studies do not prove the causality of interventions on outcomes. In our meta-analysis, there was no evidence showing the difference of dose intervention of fish oil supplementation on insulin sensitivity.

Our study suggested that short-term fish oil supplementation was beneficial for insulin sensitivity than long-term intervention. Additionally, the previous study has reported that serum PUFA levels reaching equilibrium needed 4 weeks at least [26]. Combining with the results of our research, long-term treatment duration intervention was not effective on insulin sensitivity either. Therefore, the best intervention period might be short-term, which is less than 12 weeks but at least over 4 weeks. Due to the serum biomarkers' metabolism period, duration of the intervention can be critical for the study. As the reasons mentioned, more studies are needed to explain the duration related difference. The dose of n-3 PUFA did not affect the insulin sensitivity in our research. In Akinkuolie et al.'s study, he focused on the relationship between n-3 PUFA and insulin sensitivity. Therefore, he included the studies all containing $n-3$ PUFA, such as fish oil supplementation, and plantderived n-3 PUFA (flaxseeds). It is reported that the conversion of plant-derived n-3 PUFA to DHA is relatively worse than fish oil supplementation though [4]. Therefore, it would be inappropriate to combine the 
studies with plant-derived and fish-derived n-3 PUFA interventions together. Our study is more accurate on fish oil supplementation and insulin sensitivity, which could reduce bias.

Potential mechanisms could explain the association between fish oil supplements and insulin sensitivity. Nutraceuticals and functional food ingredients are beneficial to insulin resistance and dyslipidemia through decreasing 7ahydroxylase, 3-hydroxy-3-methylglutaryl-CoA, very lowdensity lipoprotein [42]. Lee et al. also suggested that polyunsaturated fatty acid-based dietary supplements could improve biomarkers related metabolic syndrome [43]. It is well recognized that Insulin sensitivity/resistance is associated with metabolic syndrome tightly [41]. The main signs of metabolic syndrome are visceral obesity, hypertension, evaluated fasting serum triglyceride level, impaired fasting glucose, insulin resistance, or pre-diabetes. Adiposity increases the risk of diabetes and reduces insulin sensitivity through the fat tissue release inflammatory markers, insulin-like growth factors (IGF), sCD163 and adipokines [44-46]. Thus, it is biologically plausible that fish oil supplementation could improve insulin sensitivity among people with metabolic disorders.

\section{Strengths and limitations}

This meta-analysis was an updated and comprehensive investigation on the effects of fish oil supplementation and insulin sensitivity. We included RCTs, which avoids the influence of bias of observational studies.

There are several limitations that should be acknowledged in our study. One of the limitations of this metaanalysis is the quality of methodologies across the trials included. Some of the trials were not blinded well or randomized properly. However, sensitivity analysis showed that the results maintained robust. Well-designed RCTs are needed to perform in the future. Secondly, our study did not address the issues related to the age of participants. It is reported that the change of insulin sensitivity might be along with the changes of adiposity rather than being an inevitable consequence ageing [47]. The sample size of some studies included was relatively small; whose power was less than $80 \%$. In addition to methodological limitations of the original studies, dosages of fish oil supplementations were different within the different studies, which could affect the final results. However, subgroup analysis showed no different effects between the high dose and low dose group of fish oil on insulin sensitivity. As to the carry-over effect of the cross design studies included, we used the first periods of intervention before cross-over. Therefore, there was no carry-over influence [20, 48]. Finally, we assumed that most of the well-designed RCTs would have been published in English language journals. However, our comprehensive literature search and the results of non-publication bias showed that our meta- analysis was not driven by a selective publication of positive findings.

\section{Further implication}

This systematic review and meta-analysis showed that fish oil supplementation did not affect estimates of insulin sensitivity overall. However, short-term fish oil supplementation could improve insulin sensitivity among patients with metabolic disorders, which could be a significant intervention as secondary prevention for the T2DM and metabolic syndrome. The subgroup analysis suggested that there was no influence of dosage of supplementation and measure of insulin sensitivity on the outcomes. However, more interventions studies especially high-quality trials are necessary to confirm the results.

\section{Conclusion}

Take together, these findings have great implications for prevention of T2DM. The research studies in the future would be more beneficial to explicitly prescribe interventions for trials, especially the dose, frequency, administration and duration of fish oil supplementation. Additionally, more research should be done to determine the population who could benefit from the intervention.

\section{Abbreviations}

BMI: Body mass index; PRIMA: Preferred Reporting Items for Systematic Reviews and Meta-Analysis; PUFA: Polyunsaturated fatty acids;

QUICKI: Quantitative Insulin Sensitivity Check Index; RCTs: Randomized control trials; SD: Standard deviation; T2DM: Type 2 diabetes mellitus

\section{Acknowledgements \\ We are grateful for the valuable suggestion from reviewers of this manuscript. \\ Funding \\ This research was supported by Chongqing Municipal Health Bureau 2009-1-57. \\ Author's contributions \\ $\Pi \mathrm{G}, \mathrm{QH}$ Z, HQ G and TH were responsible for the study concept and design. $\Pi \mathrm{G}$ and $\mathrm{HQ}$ G performed the literature searches, selected available articles and methodological quality assessment. $\Pi \mathrm{G}$ and HQ G extracted data from these available reports and did the analyses. $\pi \mathrm{G}$ was responsible for the article writing. $\mathrm{QH} Z$ and $\mathrm{T} H$ revised the manuscript. All authors reviewed and approved the final manuscript.}

Ethics approval and consent to participate Not applicable.

Consent for publication

Not applicable.

Competing interests

The authors declare that they have no competing interest.

\section{Author details}

${ }^{1}$ Centre for Lipid Research, Key Laboratory of Molecular Biology on Infectious Diseases, Ministry of Education, Chongqing Medical University, Chongqing, People's Republic of China. ${ }^{2}$ Epidemiology Domain, Saw Swee Hock School of Public Health, Singapore, Singapore. ${ }^{3}$ Department of Medicine, Yong Loo Lin School of Medicine, National University of Singapore, MD1, 12 Science Drive 2, \#09-01T, Singapore 117549, Singapore. ${ }^{4}$ Department of Nursing, The First Affiliated Hospital of Chongqing Medical University, No. 1 Youyi Lu, Yuzhong District, 400016 Chongqing, People's Republic of China. 
Received: 26 April 2017 Accepted: 22 June 2017

\section{Published online: 03 July 2017}

\section{References}

1. Noto H, Tsujimoto T, Noda M. Significantly increased risk of cancer in diabetes mellitus patients: a meta-analysis of epidemiological evidence in Asians and non-Asians. J Diabetes Investig. 2012;3(1):24-33.

2. Wild S, Roglic G, Green A, Sicree R, King H. Global prevalence of diabetes: estimates for the year 2000 and projections for 2030. Diabetes Care. 2004 27(5):1047-53.

3. Akinkuolie AO, Ngwa JS, Meigs JB, Djousse L. Omega-3 polyunsaturated fatty acid and insulin sensitivity: a meta-analysis of randomized controlled trials. Clin Nutr. 2011;30(6):702-7.

4. Brinkmann C, Brixius K. Hyperlactatemia in type 2 diabetes: can physical training help? J Diabetes Complicat. 2015;29(7):965-9.

5. Li D. Omega-3 polyunsaturated fatty acids and non-communicable diseases: meta-analysis based systematic review. Asia Pac J Clin Nutr. 2015;24(1):10-5.

6. Calder PC. Functional roles of fatty acids and their effects on human health. JPEN J Parenter Enteral Nutr. 2015;39(1 Suppl):18S-32S.

7. Dall TM, Yang W, Halder P, Pang B, Massoudi M, Wintfeld N, Semilla AP, Franz J, Hogan PF. The economic burden of elevated blood glucose levels in 2012: diagnosed and undiagnosed diabetes, gestational diabetes mellitus, and prediabetes. Diabetes Care. 2014;37(12):3172-9.

8. Elbourne DR, Altman DG, Higgins JP, Curtin F, Worthington HV, Vail A. Metaanalyses involving cross-over trials: methodological issues. Int J Epidemiol. 2002:31(1):140-9.

9. Hamasaki H, Noda M, Moriyama S, Yoshikawa R, Katsuyama H, Sako A, Mishima S, Kakei M, Ezaki O, Yanai H. Daily physical activity assessed by a Triaxial accelerometer is beneficially associated with waist circumference, serum triglycerides, and insulin resistance in Japanese patients with Prediabetes or untreated early type 2 diabetes. Journal of diabetes research. 2015;2015:526201.

10. Moher D, Liberati A, Tetzlaff J, Altman DG, Group P. Preferred reporting items for systematic reviews and meta-analyses: the PRISMA statement. BMJ. 2009;339:b2535.

11. Muley A, Muley P, Shah M. ALA, fatty fish or marine $n-3$ fatty acids for preventing DM?: a systematic review and meta-analysis. Curr Diabetes Rev. 2014;10(3):158-65

12. Krysiak R, Gdula-Dymek A, Okopien B. The effect of bezafibrate and omega3 fatty acids on lymphocyte cytokine release and systemic inflammation in patients with isolated hypertriglyceridemia. Eur J Clin Pharmacol. 2011; 67(11):1109-17.

13. Rizza S, Tesauro M, Cardillo C, Galli A, lantorno M, Gigli F, Sbraccia P, Federici M, Quon MJ, Lauro D. Fish oil supplementation improves endothelial function in normoglycemic offspring of patients with type 2 diabetes. Atherosclerosis. 2009;206(2):569-74.

14. Woodman RJ, Mori TA, Burke V, Puddey IB, Watts GF, Beilin LJ. Effects of purified eicosapentaenoic and docosahexaenoic acids on glycemic control, blood pressure, and serum lipids in type 2 diabetic patients with treated hypertension. Am J Clin Nutr. 2002;76(5):1007-15.

15. Mostad IL, Bjerve KS, Bjorgaas MR, Lydersen S, Grill V. Effects of n-3 fatty acids in subjects with type 2 diabetes: reduction of insulin sensitivity and time-dependent alteration from carbohydrate to fat oxidation. Am J Clin Nutr. 2006;84(3):540-50.

16. Petersen KF, Dufour S, Savage DB, Bilz S, Solomon G, Yonemitsu S, Cline GW, Befroy D, Zemany L, Kahn BB, et al. The role of skeletal muscle insulin resistance in the pathogenesis of the metabolic syndrome. Proc Natl Acad Sci U S A. 2007;104(31):12587-94.

17. Satoh N, Shimatsu A, Kotani K, Sakane N, Yamada K, Suganami T, Kuzuya H, Ogawa Y. Purified eicosapentaenoic acid reduces small dense LDL, remnant lipoprotein particles, and C-reactive protein in metabolic syndrome. Diabetes Care. 2007;30(1):144-6.

18. Su XQ, Antonas KN, Li D. Comparison of n-3 polyunsaturated fatty acid contents of wild and cultured Australian abalone. Int J Food Sci Nutr. 2004; 55(2):149-54.

19. Wallin A, Di Giuseppe D, Orsini N, Patel PS, Forouhi NG, Wolk A. Fish consumption, dietary long-chain n-3 fatty acids, and risk of type 2 diabetes: systematic review and meta-analysis of prospective studies. Diabetes Care. 2012;35(4):918-29.

20. Yamada C, Moriyama K, Takahashi E. Association between insulin resistance and metabolic syndrome risk factors in Japanese. J Diabetes Investig. 2012; 3(2):185-90.
21. Mazidi M, Gao HK, Rezaie P, Ferns GA. The effect of ginger supplementation on serum C-reactive protein, lipid profile and glycaemia: a systematic review and meta-analysis. Food Nutr Res. 2016;60:32613.

22. Sahebkar A. Effect of niacin on endothelial function: a systematic review and meta-analysis of randomized controlled trials. Vasc Med. 2014;19(1):54-66.

23. DerSimonian R, Laird N. Meta-analysis in clinical trials. Control Clin Trials. 1986;7(3):177-88.

24. Balvers MG, Verhoeckx KC, Bijlsma S, Rubingh CM, Meijerink J, Wortelboer HM, Witkamp RF. Fish oil and inflammatory status alter the n-3 to n-6 balance of the endocannabinoid and oxylipin metabolomes in mouse plasma and tissues. Metabolomics : Official journal of the Metabolomic Society. 2012;8(6):1130-47.

25. Higgins JP, Thompson SG, Deeks JJ, Altman DG. Measuring inconsistency in meta-analyses. BMJ (Clinical research ed). 2003;327(7414):557-60.

26. Kondo K, Morino K, Nishio Y, Kondo M, Nakao K, Nakagawa F, Ishikado A, Sekine O, Yoshizaki T, Kashiwagi A, et al. A fish-based diet intervention improves endothelial function in postmenopausal women with type 2 diabetes mellitus: a randomized crossover trial. Metab Clin Exp. 2014;63(7):930-40.

27. Laufs U, Schirmer SH. Margarines supplemented with low dose n-3 fatty acids are not effective in secondary prevention. Eur Heart J. 2012;33(13): 1555-7.

28. Rivellese AA, Maffettone A, lovine C, Di Marino L, Annuzzi G, Mancini M, Riccardi G. Long-term effects of fish oil on insulin resistance and plasma lipoproteins in NIDDM patients with hypertriglyceridemia. Diabetes Care. 1996;19(11):1207-13.

29. Kabir M, Skurnik G, Naour N, Pechtner V, Meugnier E, Rome S, QuignardBoulange A, Vidal H, Slama G, Clement K, et al. Treatment for 2 mo with n 3 polyunsaturated fatty acids reduces adiposity and some atherogenic factors but does not improve insulin sensitivity in women with type 2 diabetes: a randomized controlled study. Am J Clin Nutr. 2007:86(6):1670-9.

30. Sarbolouki S, Javanbakht MH, Derakhshanian H, Hosseinzadeh P, Zareei M, Hashemi SB, Dorosty AR, Eshraghian MR, Djalali M. Eicosapentaenoic acid improves insulin sensitivity and blood sugar in overweight type 2 diabetes mellitus patients: a double-blind randomised clinical trial. Singap Med J. 2013;54(7):387-90.

31. Chan DC, Watts GF, Barrett PH, Beilin LJ, Redgrave TG, Mori TA. Regulatory effects of HMG CoA reductase inhibitor and fish oils on apolipoprotein B100 kinetics in insulin-resistant obese male subjects with dyslipidemia. Diabetes. 2002:51(8):2377-86.

32. Kelley DS, Adkins Y, Woodhouse LR, Swislocki A, Mackey BE, Siegel D. Docosahexaenoic acid supplementation improved lipocentric but not glucocentric markers of insulin sensitivity in hypertriglyceridemic men. Metab Syndr Relat Disord. 2012;10(1):32-8.

33. Spencer M, Finlin BS, Unal R, Zhu B, Morris AJ, Shipp LR, Lee J, Walton RG, Adu A, Erfani $R$, et al. Omega-3 fatty acids reduce adipose tissue macrophages in human subjects with insulin resistance. Diabetes. 2013; 62(5):1709-17.

34. Olza J, Mesa MD, Aguilera CM, Moreno-Torres R, Jimenez A. Perez de la Cruz a, Gil a: influence of an eicosapentaenoic and docosahexaenoic acidenriched enteral nutrition formula on plasma fatty acid composition and biomarkers of insulin resistance in the elderly. Clin Nutr. 2010:29(1):31-7.

35. Abete I, Parra D, Crujeiras AB, Goyenechea E, Martinez JA. Specific insulin sensitivity and leptin responses to a nutritional treatment of obesity via a combination of energy restriction and fatty fish intake. Journal of human nutrition and dietetics : the official journal of the British Dietetic Association. 2008:21(6):591-600.

36. Bryhni $B$, Jenssen TG, Olafsen $\mathrm{K}$, Eikrem JH. Age or waist as determinant of insulin action? Metab Clin Exp. 2003:52(7):850-7.

37. Crochemore IC, Souza AF, de Souza AC. Rosado EL: omega-3 polyunsaturated fatty acid supplementation does not influence body composition, insulin resistance, and lipemia in women with type 2 diabetes and obesity. Nutrition in clinical practice : official publication of the American Society for Parenteral and Enteral Nutrition. 2012;27(4):553-60.

38. Curtin F, Altman DG, Elbourne D. Meta-analysis combining parallel and cross-over clinical trials. I: continuous outcomes. Stat Med. 2002;21(15): 2131-44

39. Fakhrzadeh $H$, Ghaderpanahi M, Sharifi F, Mirarefin M, Badamchizade Z, Kamrani AA, Larijani B. The effects of low dose $n-3$ fatty acids on serum lipid profiles and insulin resistance of the elderly: a randomized controlled 
clinical trial. International journal for vitamin and nutrition research Internationale Zeitschrift fur Vitamin- und Ernahrungsforschung Journal international de vitaminologie et de nutrition. 2010;80(2):107-16.

40. Farsi PF, Djazayery A, Eshraghian MR, Koohdani F, Saboor-Yaraghi AA, Derakhshanian H, Zarei M, Javanbakht MH, Djalali M. Effects of supplementation with omega-3 on insulin sensitivity and non-esterified free fatty acid (NEFA) in type 2 diabetic patients. Arq Bras Endocrinol Metabol. 2014:58(4):335-40.

41. Jialal I, Devaraj S. Vitamin E supplementation and cardiovascular events in high-risk patients. N Engl J Med. 2000;342(25):1917-8.

42. Scicchitano P, Cameli M, Maiello M, Modesti PA, Muiesan ML, Novo S, Palmiero P, Saba PS, Pedrinelli R, Ciccone MM. Nutraceuticals and dyslipidaemia: beyond the common therapeutics. J Funct Foods. 2014;6:11-32.

43. Lee TC, Ivester P, Hester AG, Sergeant S, Case LD, Morgan T, Kouba EO, Chilton $\mathrm{FH}$. The impact of polyunsaturated fatty acid-based dietary supplements on disease biomarkers in a metabolic syndrome/diabetes population. Lipids Health Dis. 2014;13:196.

44. Rose DP, Gracheck PJ, Vona-Davis L. The interactions of obesity, inflammation and insulin resistance in breast cancer. Cancers (Basel). 2015; 7(4):2147-68.

45. Phillips $L K$, Prins JB. The link between abdominal obesity and the metabolic syndrome. Curr Hypertens Rep. 2008;10(2):156-64.

46. Toupchian O, Sotoudeh G, Mansoori A, Nasli-Esfahani E, Djalali M, Keshavarz SA, Koohdani F. Effects of DHA-enriched fish oil on monocyte/macrophage activation marker SCD163, asymmetric dimethyl arginine, and insulin resistance in type 2 diabetic patients. J Clin Lipidol. 2016;10(4):798-807.

47. Roberts CK, Hevener AL, Barnard RJ. Metabolic syndrome and insulin resistance: underlying causes and modification by exercise training. Comprehensive Physiology. 2013;3(1):1-58.

48. Toft I, Bonaa KH, Ingebretsen OC, Nordoy A, Jenssen T. Effects of n-3 polyunsaturated fatty acids on glucose homeostasis and blood pressure in essential hypertension. A randomized, controlled trial. Ann Intern Med. 1995:123(12):911-8.

\section{Submit your next manuscript to BioMed Central and we will help you at every step:}

- We accept pre-submission inquiries

- Our selector tool helps you to find the most relevant journal

- We provide round the clock customer support

- Convenient online submission

- Thorough peer review

- Inclusion in PubMed and all major indexing services

- Maximum visibility for your research

Submit your manuscript at www.biomedcentral.com/submit 